\title{
Prevalence of metabolic syndrome in children from central Mexico
}

\author{
E. J. Vargas-Garcia, C. E. L. Evans and J. E. Cade \\ School of Food Science and Nutrition, University of Leeds, Leeds, LS2 9JT, UK
}

\section{E.J. Vargas-Garcia awarded the FSAI student prize for poster communication}

Childhood obesity rates remain alarmingly high in middle-income countries such as Mexico. The Metabolic Syndrome (MS) has been identified as a co-morbidity in obese younger populations which increases the risk of cardiovascular disease later in life. The Ministry of Health in Guanajuato State, Mexico in 2009 carried out a survey in 899,000 children to monitor their weight, height and thus BMI. An additional biochemical analysis was later performed in 10,798 children who had been identified to be at greater risk of suffering from MS. The aim of the present study was to determine the prevalence of MS according to the International Diabetes Federation Criteria for children ${ }^{(1)}$ in a sample of 6 to 15 year olds living in central Mexico. Components of MS measured were high triglycerides, high fasting glucose and low HDL-C levels, in addition to the presence of obesity in certain subjects.

\begin{tabular}{|c|c|c|c|c|c|}
\hline \multirow[b]{3}{*}{ Nutritional Status } & \multicolumn{4}{|l|}{ Mexican children } & \multirow{3}{*}{$\begin{array}{l}\text { UK children }^{(2)} \\
12-18 \text { year olds } \\
(n=152)\end{array}$} \\
\hline & \multicolumn{2}{|c|}{$6-9$ year olds $(n=3245)$} & \multicolumn{2}{|c|}{$10-15$ year olds $(n=3090)$} & \\
\hline & $\begin{array}{l}3 \text { or more } \\
\text { components of } \\
\text { MS (n) }\end{array}$ & $\%(95 \% \mathrm{CI})$ & $\begin{array}{l}3 \text { or more } \\
\text { components of } \\
\text { MS (n) }\end{array}$ & $\%(95 \% \mathrm{CI})$ & \\
\hline $\begin{array}{l}\text { Undernourished }\left(\mathrm{BMI}<5^{\text {th }}\right. \\
\text { percentile) } n=149\end{array}$ & 2 & $1 \cdot 3(0 \cdot 0-3 \cdot 2)$ & 0 & - & \\
\hline $\begin{array}{l}\text { Normal (BMI }>5^{\text {th }}<85^{\text {th }} \\
\text { percentile) } n=2050\end{array}$ & 16 & $0 \cdot 8(0 \cdot 4-1 \cdot 2)$ & 19 & $0 \cdot 9(0 \cdot 5-1 \cdot 3)$ & \\
\hline $\begin{array}{l}\text { Overweight (BMI } \geq 85^{\text {th }} \\
\text { percentile) } n=1428\end{array}$ & 14 & $1 \cdot 0(0 \cdot 5-1 \cdot 5)$ & 34 & $2 \cdot 4(1 \cdot 6-3 \cdot 2)$ & \\
\hline $\begin{array}{l}\text { Obese (BMI } \geq 95^{\text {th }} \\
\text { percentile) } n=2708\end{array}$ & 324 & $12 \cdot 0(10 \cdot 7-13 \cdot 2)$ & 368 & $13 \cdot 6(12 \cdot 3-14 \cdot 9)$ & $14 \cdot 5(8 \cdot 9-20 \cdot 1)$ \\
\hline Total $=6335$ & 356 & $5 \cdot 6(5 \cdot 0-6 \cdot 2)$ & 421 & $6 \cdot 7(6 \cdot 1-7 \cdot 3)$ & \\
\hline
\end{tabular}

Values are presented as number of subjects that met criteria of MS within each nutritional diagnosis and percentages and $95 \%$ confidence intervals.

Data on BMI and biochemical features was available in 6335 children. Overall 12.3\% (data not shown) of the children met the criteria for MS. In comparison to UK data, prevalence of MS in both countries was similar for obese adolescent populations $(13 \cdot 6 \%$ vs 14.5\%). The most frequent metabolic risk factor was low HDL-C (29.5\%; data not shown). Although MS was more prevalent amongst obese children, several children with normal BMI appeared to also fulfil the criteria for MS which could be suggestive of a relationship between abdominal adiposity and impaired metabolic results that has been described in normal-weight adults ${ }^{(3)}$. Surrogate measures like waist circumference are needed to further explore and confirm this.

In the light of these results, which can relate to inadequate dietary and physical activity behaviours, it is clear that more comprehensive screening activities are needed in Mexican primary health care systems along with health education campaigns on lifestyle modification to reduce the risk of developing metabolic syndrome in paediatric populations.

1. Zimmet $\mathrm{P}$, Alberti KG, Kaufman F, et al. (2007). Pediatr diabetes 8, 299-306.

2. Wei C, Ford A, Hunt L, et al. (2011). Arch Dis Child 96, 1003-1007.

3. St-Onge MP, Janssen I \& Heymsfield SB (2004). Diabetes care 27, 2222-2228. 